\title{
Environmental risks of HBCDD from construction and demolition waste: a contemporary and future issue
}

\author{
Zhiqiang $\mathrm{Nie}^{1} \cdot$ Ziliang Yang $^{1} \cdot$ Yanyan Fang ${ }^{1,3} \cdot$ Yufei Yang ${ }^{1} \cdot$ Zhenwu Tang $^{2} \cdot$ \\ Xingrun Wang $^{1} \cdot$ Qingqi Die $^{1,3} \cdot$ Xingbao Gao $^{1}$ - Fengsong Zhang ${ }^{1,4} \cdot$ Qi Wang ${ }^{1}$. \\ Qifei Huang ${ }^{1}$
}

Received: 1 April 2015 / Accepted: 21 September 2015 / Published online: 1 October 2015

(C) Springer-Verlag Berlin Heidelberg 2015

\begin{abstract}
Hexabromocyclododecane (HBCDD), as one of the most widely used brominated flame retardants (BFRs), is of great concern globally because of its persistence in the environment and negative impacts on humans and animals. HBCDD has been mainly used in flame-retarded expanded (EPS) and extruded (XPS) polystyrene foams for insulation in the construction industry. Most of these products will become a part of the construction and demolition (C\&D) waste at the end of their life cycle (30-50 years) which is typically disposed of into landfills or incineration. However, the recycling of this material takes quite a low share compared with landfill and incineration. Consequently, high environmental risks will exist in these disposal approaches due to the HBCDD in C\&D waste. Currently, XPS or EPS products containing HBCDD in the construction industry have not
\end{abstract}

Responsible editor: Philippe Garrigues

\section{Zhenwu Tang \\ zwtang@ncepu.edu.cn \\ Qifei Huang \\ huangqf@vip.sina.com}

1 State Key Laboratory of Environmental Criteria and Risk Assessment, Chinese Research Academy of Environmental Sciences, Beijing 100012, China

2 MOE Key Laboratory of Regional Energy and Environmental Systems Optimization, Resources and Environmental Research Academy, North China Electric Power University, Beijing 102206, China

3 College of Water Sciences, Beijing Normal University, Beijing 100875, China

4 Key Laboratory of Land Surface Pattern and Simulation, Institute of Geographic Sciences and Natural Resources Research, Chinese Academy of Sciences, 100101 Beijing, China reached the end of their life cycle in most countries. Relatively little attention has been paid to this emergency issue by either the government or public. Furthermore, C\&D waste is most likely disposed of by direct dumping, simple stacking, or open burning in developing countries. Therefore, this paper highlights the global environmental risks of HBCDD from C\&D waste. Areas of research for key problems of HBCDD contained in C\&D waste are suggested to help control and finally eliminate the impact.

Keywords HBCDD - Construction and demolition waste . Environmental risk $\cdot$ Scenario analysis $\cdot$ POPs $\cdot$ Stockholm Convention

\section{Introduction}

Hexabromocyclododecane (HBCDD), as one of the most widely used additive brominated flame retardants (BFRs), has received significant global concern and been added into Annex A of the Stockholm Convention (www.pops. int). This is because of its persistence in the environment and negative impacts on humans and animals (Brandsma et al. 2009; Covaci et al. 2006; Eljarrat et al. 2009). In the current research, HBCDD is proved to have accumulated in organisms and can magnify with the food chain in the upper trophic living organisms. The results of risk assessment of HBCDD in Europe have also showed high concentrations of HBCDD residues in the fishes, and the steady state BCF of HBCDD was found to be 18,100 (log $\mathrm{BCF}$ 4.26), which is used as the accumulation criterion in the assessment of HBCDD (EC 2011). To fulfill the obligations of the Stockholm Convention, there are now 179 countries willing to address the HBCDD issue and starting to manage it within their national 
implementation plans (NIPs). Reducing the HBCDD emissions would require a series of national activities including source identification and quantification, development of an emission inventory, substitution innovation, and application and implementation of best available techniques and best environmental practices (BATs/BEPs) for emission reduction. Furthermore, it would need more routine emission monitoring and management and supervision by the responsible agencies. These activities might also require large financial support. The NIP actions will be well integrated with national environmental action plans or environmental strategies to further address and reduce the HBCDD release and pollution in the world.

In 2011, global market demand for HBCDD was 31, 000 tonnes, of which about 13,000 was produced in Europe and the USA, and 18,000 in China (POPRC 2011, 2012). Over $90 \%$ of HBCDD has been extensively used in flame-retardant expanded (EPS) and extruded (XPS) polystyrene foam for insulation in the construction industry with a long service life (30 to 50 years), while the use in textile applications and electric and electronic appliances (high-impact polystyrene (HIPS)) is of a smaller scale. Although the volume is small, studies have found that the exposure from the uses of HBCDD as textiles and electronics also has relative high risk (EU 2011). Both the Basel and Stockholm Conventions advocate HBCDD production and use to be eliminated with a limited exemption in construction materials, and a labeling or marking system for separating EPS or XPS containing HBCDD from other building materials is needed in its life cycle.

In Europe, HBCDD in insulation began in the 1980s (EU 2011). The volume of construction and demolition (C\&D) wastes containing HBCDD is expected to increase greatly after 2030 (POPRC 2011), as buildings containing insulation flame retarded with HBCDD are refurbished or demolished. It is estimated that $\mathrm{C} \& \mathrm{D}$ waste containing HBCDD in 2030 will be approximately 156,000 tonnes in Europe (EC 2011). In developing countries, such as China, substantial C\&D waste containing HBCDD will also be generated. In China, XPS and EPS boards containing HBCDD in the construction industry began in 2001, and their usage volume was 36 million cubic meters in 2012 (CSES 2014). The amount of XPS/EPS insulation boards reached at least 1 million tonnes, most of which will become $C \& D$ waste at the end of their life cycle in 2030 to 2060. However, environmental risks of HBCDD from $\mathrm{C} \& \mathrm{D}$ waste have not received enough attention by governments and the public. The purpose of this paper is to highlight the global environmental risks of HBCDD from $C \& D$ waste. Areas of research for key problems of HBCDD contained in C\&D waste are suggested to help control and finally eliminate the impact.
End-of-life scenarios analysis of HBCDD from C\&D waste

\section{Reuse and recycling}

The separated EPS or XPS insulation materials are recyclable The end of life for EPS and XPS often generates when buildings are demolished or refurbished. EPS and XPS insulation may remain functional as insulation even after a building is out of service. Polystyrene insulation can therefore be salvaged and reused, although the board must be protected and not broken during the removal (USEPA 2014). For example, during the re-roofing of the Dallas Fort Worth International Airport, approximately $90 \%$ of existing XPS material had maintained its thermal and physical properties over the past 17 years and then been reused (Owens Corning 2007). Additionally, polystyrene insulation boards including EPS or XPS can be ground up and molded with virgin EPS or XPS to form new boards (EC 2008; Hart 2007). Around 45, 400 and 25,000 tonnes, respectively, of polystyrene and polyurethane are produced in Portugal each year (INE 2007a). According to the recycle rate (below $40 \%$ ) given for Portugal in Europe (EC 2011), the recycle of these materials is still at quite a large scale. However, according to previous studies, HBCDD-containing EPS/XPS which have been partly recycled in packaging including food packaging were found to have potential exposure risk and in buoy with related risk to aquatic organisms (Rani et al. 2014; Hong et al. 2013). Therefore, after the recycling initiated in the Netherlands and Finland, the recycling of HBCDD-containing EPS and XPS is now not exempted by the Stockholm Convention.

The recycling rate of EPS or XPS insulation materials is relatively low The recycling rate for the inert fraction of C\&D waste (concrete waste, scrap steel, cement, stone and brick, and others) exceeds $70 \%$ in developed countries, including several EU countries, Japan, and USA (EC 2011; POPRC 2011; Rodríguez et al. 2015; USEPA 2014). However, the recycling process lacks practical techniques or a labeling/ marking system for separating EPS or XPS containing HBCDD from other building materials (Coelho and de Brito 2013; POPRC 2011), and the collection and recycling of used EPS or XPS materials have been greatly hindered. The recycling rate of C\&D waste containing EPS and XPS in most countries remains relatively low (only $30 \%$ in EU) (EC 2011). No relevant data have been found for the USA (USEPA 2014). In most developing countries, the situation is even worse than the developed economics. In China, the recycling rate of general C\&D waste is only $5 \%$ (NDRC 2014), and large amounts of EPS or XPS building materials containing HBCDD have not reached the end of their life cycle. Most of this waste is mostly dumped or landfilled at life cycle end. 


\section{Landfilling and incineration}

The environmental risks of EPS or XPS insulation waste containing HBCDD in landfill sites cannot be neglected Substance flow analysis in Japan and Switzerland highlights landfills as long-term sources of HBCDD release (Managaki et al. 2009; Morf et al. 2008; Weber et al. 2011). Earlier studies have also generally found release of BFRs from landfills in Sweden, Japan, and Canada, where HBCDD was widely detected in the environmental mediums, and in Sweden, the HBCDD in the water, air, and sediment of the landfill is detected to be $3 \sim 9 \mathrm{ng} / \mathrm{L}, 0.013 \sim 0.18 \mathrm{ng} / \mathrm{m}^{3}$, and $<0.1 \mu \mathrm{g} / \mathrm{kg}$ d.w. (Remberger et al. 2004; Danon-Schaffer et al. 2014; Osako et al. 2004). Weathering and degradation (via microorganisms, UV light, and physical impact) will cause C\&D waste to release HBCDD over time to the soil and, to a less extent, to water and air (EC 2008). Furthermore, much high concentrations of HBCDD - a maximum of 36,000 ng/g dry weightare found in the particulate phase of leachate water in the Netherlands (Morris et al. 2004), especially when there is organic matter contained in the landfilling waste, which can in some degree accelerate the release of BFRs including HBCDD even at a low concentration (Kajiwara et al. 2014). However, studies on the release mechanisms of HBCDD from landfilled waste are not clear. In particular, thorough knowledge of environmental partitioning at aqueous- to solid-phase interfaces is insufficient, such as the characterization of HBCDD release to surrounding environmental media. Further, no systematic studies on environmental risks on HBCDD from C\&D waste have been done for landfilling sites or stockpiling sites, and risk controls of such HBCDD waste have not been implemented. As many counties where regulated landfills are located lack funds, few protective measures are adopted at landfill sites. Therefore, $C \& D$ waste is disposed of randomly by direct dumping or simple stacking. HBCDD releases from these wastes may be more serious.

EPS or XPS insulation waste could be partly disposed of by incineration, and it is studied that through incineration, the HBCDD contained in the polystyrene foam from building and construction market can be greatly destroyed with a rate of $99.9 \%$, but there are still unknown environmental risks in the process of incineration (Mark et al. 2015). Incineration of HBCDD and wastes under certain conditions can form polybrominated dibenzo- $p$-dioxins and dibenzofurans (PBDD/PBDF) (PE 2014), while the formation and release of PBDD/PBDF in BAT/BEP incinerators are of minor concern (Mark et al. 2015; Weber and Kuch 2003). However, it is noted that the incomplete combustion of polystyrene foams including HBCDD will generate high levels of PBDD/Fs $\left(5 \mathrm{ng} \mathrm{g}^{-1}\right.$ polystyrene ${ }^{-1}$ ) (Ebert and Bahadir 2003). Since there is lack of risk awareness and adequate scientific research, there is no emission restriction for HBCDD and PBDD/ PBDF in the incineration of EPS or XPS insulation waste in nearly all countries. Especially in developing countries, there exist great possibilities of PBDD/PBDF formation in waste incineration and open burning on landfill and backyards, and some poor people of these countries even use EPS and XPS in ovens. All these open burning, poorly functioning incinerators, and accidental fires of buildings can augment the release of PBDD/PBDF in HBCDD contained in C\&D waste.

\section{Conclusion and recommendations}

Within the frame of the Stockholm Convention, a HBCDD inventory guidance has been developed (Secretariat of the Stockholm Convention 2015) and parties to the convention will develop inventories and action plans to manage HBCDD-containing materials within their national implementation plans and related projects partly supported by GEF. With the Basel Convention, a guideline for environmentally sound management of HBCDD-containing wastes has been developed (Secretariat of the Basel Convention 2014). The Basel Convention summarizes the identification methods of HBCDD waste, such as the HBCDD wastes from production facilities, the mixture production processes and all the potential segments HBCDD wastes including C\&D waste may generate in its life cycle. The convention also provides overall process guidelines for environmentally sound management (ESM) of HBCDD-containing wastes, including contents from the sampling, analysis, monitoring, transportation, collection, packaging, labeling, and storage, and guidelines for the end-of-life management. Furthermore, disposal methods of HBCDD wastes such as preprocessing and destruction and irreversible transformation methods are proposed in the convention. Meanwhile, more attention should be paid to the destruction rate of HBCDD and PBDD/PBDF emissions from HBCDD wastes. Besides, the extended producer responsibility of HBCDD and of HBCDD-containing EPS and XPS is regulated in the OECD guidance document (OECD 2001). However, the potential long-term environmental risks of HBCDD from C\&D waste are still apparent and have not been fully addressed. To meet the requirements of the conventions and control these risks, extensive research on scientific problems of HBCDD from C\&D waste is necessary; although the Basel Convention developed a technical guidance for ESM of HBCDD-containing waste (Secretariat of the Basel Convention 2014), effective and specific controlling measures are still needed from policy-makers. Firstly, generation and flows of HBCDD from C\&D waste should be well understood, and an appropriate inventory for HBCDD emissions from that waste is required. Secondly, studies on the release mechanisms of HBCDD from C\&D waste and their environmental fate are important, on this basis, to evaluate the impacts of stack, landfill, and incineration of the C\&D waste containing HBCDD on the surrounding environment under various 
scenarios, and to establish the standards for pollutant discharge control. Thirdly, a key research topic is the development of safe treatment technologies for $\mathrm{C} \& \mathrm{D}$ waste containing HBCDD, such as co-processing of the waste in cement kilns, which is suitable for developing countries. Finally, life cycle assessment (LCA) analysis on the C\&D waste management could be strengthened to lower environmental impacts across all life cycle stages.

Acknowledgments This research was supported by the National Natural Science Foundation of China (grant nos. 21407137, 41001329, 21377121, and 41201513) and the State Key Laboratory of Environmental Criteria and Risk Assessment, Chinese Research Academy of Environmental Sciences (SKLECRA 2015OFP01 and 2014OFP04).

\section{References}

Brandsma SH, Van der Ven LT, de Boer J, Leonards PE (2009) Identification of hydroxylated metabolites of hexabromocyclododecane in wildlife and 28-days exposed Wistar rats. Environ Sci Technol 43(15):6058-63

Chinese Society of Environmental Science (CSES) (2014) The annual output of building insulation materials in China. Forum of hexabromocyclododecane (HBCDD) to the environment

Coelho A, de Brito J (2013) Economic viability analysis of a construction and demolition waste recycling plant in Portugal - part I: location, materials, technology and economic analysis. J Clean Prod 39:338-352

Covaci A, Gerecke AC, Law RJ, Voorspoels S, Kohler M, Heeb NV, Leslie H, Allchin CR, de Boer J (2006) Hexabromocyclododecanes (HBCDs) in the environment and humans: a review. Environ Sci Technol 40(12):3679-88

Danon-Schaffer MN, Grace JR, Ikonomou MG (2014) Investigation of PBDEs in landfill leachates from across Canada. Environ Manag Sustain Dev 3(1):74

Ebert J, Bahadir M (2003) Formation of PBDD/F from flame-retarded plastic materials under thermal stress. Environ Int 29(6):711-716

Eljarrat E, Guerra P, Martínez E, Farré M, Alvarez JG, López-Teijón M, Barceló D (2009) Hexabromocyclododecane in human breast milk: levels and enantiomeric patterns. Environ Sci Technol 43(6):1940-6

European Commission (EC), 2008. Risk assessment hexabromocyclodode, Final Report. http://ecb.jrc.ec.europa.eu/documents/ExistingChemicals/RISK_ASSESSMENT/REPORT/hbcddreport044.pdf

European Commission (EC), 2011. Study on waste related issues of newly listed POPs and candidate POPs, final report. Available at: http:// ec.europa.eu/environment/waste/studies/pdf/POP_Waste_2011.pdf

Hart GH (2007) A good business move: recycling insulation materials. Natl. Insul. Assoc. J. Insul. Outlook. Available online at. http:// www.insulation.org/articles/article.cfm.

Hong SH, Jang M, Rani M, Han GM, Song YK, Shim WJ (2013) Expanded polystyrene (EPS) buoy as a possible source of hexabromocyclododecanes (HBCDDs) in the marine environment. Organohalogen Compd 75:882-885

INE (2007) Industrial production statistics (year 2007) (in Portuguese). Statistics Portugal. Available online at. http://www.ine.pt

Kajiwara N, Hirata O, Takigami H, Noma Y, Tachifuji A, Matsufuji Y (2014) Leaching of brominated flame retardants from mixed wastes in lysimeters under conditions simulating landfills in developing countries. Chemosphere 116:46-53

Managaki S, Miyake Y, Yokoyama Y, Hondo H, Masunaga S, Nakai S, Kobayashi T, Kameya T, Kimura A, Nakarai T, Oka Y, Otani H, Miyake A (2009) Emission load of hexabromocyclododecane in
Japan based on the substance flow analysis. Organohalogen Compounds 2471-2476. Available at: http://risk.kan.ynu.ac.jp/ publish/managaki/managaki200908_1.pdf

Mark FE, Vehlow J, Dresch H, Dima B, Grüttner W, Horn J (2015) Destruction of the flame retardant hexabromocyclododecane in a fullscale municipal solid waste incinerator. Waste Manag Res 33:165-174

Morf L, Buser A, Taverna R, Bader HP, Scheidegger R (2008) Dynamic substance flow analysis as a valuable tool - a case study for brominated flame retardants as an example of potential endocrine disruptors. CHIMIA Int J Chem 62(5):424-431

Morris S, Allchin CR, Zegers BN, Haftka JJH, Boon JP, Belpaire C, Leonards PEG, van Leeuwen SPJ, de Boer J (2004) Distribution and fate of HBCDD and TBBPA brominated flame retardants in North Sea estuaries and aquatic food webs. Environ Sci Technol 38:5497-5504

NDRC (2014) Report of comprehensive utilization of resources in China. Nat Dev Reform Comm (NDRC) 10:50-56

OECD (2001) Extended producer responsibility: a guidance manual for governments. OECD, Paris

Osako M, Kim YJ, Sakai S (2004) Leaching of brominated flame retardants in leachate from landfills in Japan. Chemosphere 57:1571-1579

Owens Corning (2007) PINK insulation shows true color is green: FOAMULAR $^{\circledR}$ extruded insulation recycled after 17 years on the job at DFW airport

Persistent Organic Pollutants Review Committee (POPRC) (2011) Addendum to the risk management evaluation on hexabromocyclododecane (UNEP/POPS/POPRC.7/19/Add.1)

Persistent Organic Pollutants Review Committee (POPRC) (2012) Addendum to the risk management evaluation on hexabromocyclododecane (UNEP/POPS/POPRC.8/16/Add.3)

Plastics Europe (PE) (2014) End-of-life treatment of HBCDD-containing polystyrene insulation foams: large-scale demonstration of the treatment of expanded polystyrene foam (EPS) and 2-16 extruded polystyrene foam (XPS) containing hexabromocyclododecane (HBCDD) as a flame-retardant by co-incineration in the Würzburg Municipal Solid Waste Incinerator. Technical Summary Report

Rani M, Shim WJ, Han GM, Jang M, Song YK, Hong SH (2014) Hexabromocyclododecane in polystyrene based consumer products: an evidence of unregulated use. Chemosphere 110:111-119

Remberger M, Sternbeck J, Palm A, Kaj L, Strömberg K, BrorströmLundén E (2004) The environmental occurrence of hexabromocyclododecane in Sweden. Chemosphere 54:9-21

Rodríguez G, Medina C, Alegre FJ, Asensio E, Sanchez De Rojas MI (2015) Assessment of construction and demolition waste plant management in Spain: in pursuit of sustainability and eco-efficiency. $\mathrm{J}$ Clean Prod 90:16-24

Secretariat of the Basel Convention (2014) Draft technical guidelines for the environmentally sound management of wastes consisting of, containing or contaminated with hexabromocyclododecane. http:// www.basel.int/Implementation/POPsWastes/TechnicalGuidelines/ tabid/2381/Default.aspx

Secretariat of the Stockholm Convention (2015) Guidance for the identification and substitution of hexabromocyclododecane. Draft April 2015 http://chm.pops.int/Implementation/NIPs/Guidance/tabid/ 2882/Default.aspx

USEPA. 2014. Flame retardant alternatives for hexabromocyclododecane (HBCDD). Chapter 2 HBCDD uses, end-of-life, and exposure, final report. Available at: www.epa.gov

Weber R, Kuch B (2003) Relevance of BFRs and thermal conditions on the formation pathways of brominated and brominated-chlorinated dibenzodioxins and dibenzofurans. Environ Int 29:699-710

Weber R, Watson A, Forter M, Oliaei F (2011) Persistent organic pollutants and landfills - a review of past experiences and future challenges. Waste Manag Res 29(1):107-121 